\title{
PENILAIAN KONDISI KESEHATAN LINGKUNGAN PUSKESMAS RAWAT INAP DI KECAMATAN KUTOWINANGUN KABUPATEN KEBUMEN TAHUN 2015
}

\author{
Nilna Syarifatun Nisa ${ }^{1}$, Teguh Widiyanto ${ }^{2)}$ \\ Jurusan Kesehatan Lingkungan, Politeknik Kesehatan Kemenkes Semarang, \\ Jl. Raya Baturaden KM 12 Purwokerto, Indonesia
}

\begin{abstract}
Abstrak
Puskesmas merupakan sarana kesehatan terdepan yang memberikan pelayanan langsung kepada masyarakat. Penyehatan sarana dan bangunan Puskesmas sangat penting dalam mewujudkan lingkungan yang sehat yang dapat memberikan perlindungan bagi pengunjung dan petugas Puskesmas.Tujuan penelitian untuk menilai kondisi kesehatan lingkungan Puskesmas Rawat Inap Kutowinangun menggunakan metode penelitian deskriptif dengan cara observasi dan wawancara. Kondisi kesehatan lingkungan menunjukan bahwa rata-rata temperatur adalah $28,25^{\circ} \mathrm{C}$, kelembaban $66 \%$ dan intensitas cahaya adalah 159lux, lingkungan dan bangunan bagian dalam dan luar dikategorikan baik dengan persentase $74 \%$, penyediaan air bersih dikategorikan sangat baik dengan persentase 100\%, sarana pembuangan air limbah dikategorikan baik dengan persentase $83 \%$, pengelolaan sampah dikategorikan cukup dengan persentase $55 \%$, pengolahan makanan dan minuman dikategorikan baik dengan persentase $75 \%$, tempat pencuciaan dikategorikan kurang dengan persentase $37 \%$, fasilitas penunjang dikategorikan cukup persentase 50\%. Simpulkan menunjukan kondisi kesehatan lingkungan Puskesmas Rawat Inap Kutowinangun secara keseluruhan persentase 66\% dengan kategori baik. Peneliti menyarankan dilakukan pengukuran kuantitas air bersih, kualitas air bersih secara biologi dan kimia serta mengukur data infeksi nosocomial dan BOR.
\end{abstract}

Kata kunci : kondisi kesehatan lingkungan, kesehatan lingkungan

\begin{abstract}
PHC is a leading healthcare facility that provides services directly to the public. Sanitation facilities and health center building is very important in constructing a healthy environment that can provide protection for visitors and health center staff. The research objective was assessing the environmental health conditions of Inpatient Public Health Center Kutowinangun District using descriptive research method through observation and interview. The environmental health assessment results shows that the average temperature was $28,25^{\circ} \mathrm{C}$ and $66 \%$ humidity, average light intensity was 159 lux, the inside and outside building categorized as "good" with the percentage value $74 \%$, provision was categorized as "very good" with percentage value $100 \%$, wastewater disposal was categorized as "good" with percentage value $83 \%$, waste management considered as "fair" with percentage value 55\%, food and beverage processing categorized as "good" with percentage value 75\%, the cutlery washing place categorized as "bad" with percentage value 37\%, supporting facilities was categorized as "fair with percentage value 50\%. The research conclusion drawn was; the environmental health conditions of Kutowinangun Inpatient Public Health Center overall percentage value was $66 \%$ categorized as "good". The researcher suggested to conducting clean water quantity and quality measurements, both biologically and chemically and also measuring the nosocomial infection
\end{abstract}

Keywords : Environmental Health Condition, environmenthal health

\section{PENDAhuluan}

Menurut UU No 36 Tahun 2009 pasal 163 tentang kesehatan lingkungan yaitu: pemerintah dan masyarakat menjamin ketersediaan lingkungan yang sehat dan tidak mempunyai resiko buruk bagi kesehatan.

Kesehatan lingkungan meliputi aspek dari kesehatan manusia, termasuk kualitas hidup, yang ditentukan oleh fisik, biologi, kimia, faktor sosial dan psikososial dalam lingkungan. Hal ini juga mengacu

1) E-mail: nilnasn15@gmail.com

2) E-mail: widiyantoteguh@yahoo.com pada teori dan praktek menilai, mengoreksi dan mencegah faktor-faktor tersebut di lingkungan yang berpotensi dapat mempengaruhi kesehatan generasi sekarang dan masa depan (WHO, 1993)

Saat ini Puskesmas sebagai salah satu sarana pelayanan kesehatan tingkat pertama sebelum dirujuk ke Rumah Sakit yang lebih besar dan merupakan tempat umum yang beresiko potensial bagi penularan penyakit maupun pencemaran lingkungan. Sekarang puskesmas dalam peran masa BBJS mengakibatkan 
naiknya permintaan masyarakat untuk mendapatkan pelayanan kesehatan. Puskesmas dengan pelayanan rawat jalan maupun rawat inap hendaknya memiliki lingkungan yang nyaman dan menyenangkan bagi pasien sebagai kesan pertama tentang puskesmas tersebut.

Puskesmas Rawat Inap merupakan puskesmas yang diberi tambahan ruangan dan fasilitas untuk menolong pasien gawat darurat, baik berupa tindakan operatif terbatas maupun asuhan keperawatan sementara dengan kapasitas kurang lebih 10 tempat tidur (P.Wulansari, 2013)

Menurut data yang diperoleh dari Dinas Kesehatan Kabupaten Kebumen tahun 2013, Kabupaten Kebumen memiliki 10 Puskesmas Rawat Inap dengan kapasitas tempat tidur 8-25 dan jenis Pelayanan UGD, KIA, kesehatan gigi dan mulut, poli umum, persalinan, konsultasi gizi, KB, klinik sanitasi, laboratorium dan radiologi. Puskesmas yang mempunyai kapasitas tempat tidur lebih dari 15 diantaranya Puskesmas Rawat Inap Prembun, Kutowinangun, dan Gombong satu. Jumlah fasilitas yang dimiliki puskesmas umumnya bervariatif sesuai dengan kepadatan pengunjung dan pasien yang datang.

Salah satu sarana umum adalah tempat pelayanan kesehatan. Permasalahan sampai saat ini pelayanan kesehatan diketahui bahwa penyakit terbanyak yang terdapat di wilayah kerja puskesmas didominasi oleh penyakit yang berhubungan dengan masalah kesehatan lingkungan. Setiap tempat atau sarana pelayanan umum wajib memelihara dan meningkatkan lingkungan yang sehat sesuai dengan standar dan persyaratan. Dari data Inspeksi kesehatan lingkungan Puskesmas yang dilakukan oleh Dinas Kesehatan perihal gerakan Puskesmas bersih dan sehat, data Inspeksi Sanitasi Puskesmas Rawat Inap Prembun presentase hasil 74\% sementara Puskesmas Rawat Inap Gombong presentase hasil 58\% dan Puskesmas Kutowinangun persentase hasil 53\%. Berdasarkan hasil tersebut Puskesmas Rawat Inap Kutowinangun memiliki presentase nilai yang paling rendah maka peneliti memilih puskesmas Rawat Inap Kutowinangun. Puskesmas Rawat Inap Kutowinangun memiliki 8 kamar dengan 22 tempat tidur.

Hasil survei pendahuluan Puskesmas Rawat Inap Kutowinangun ditemukan beberapa masalah kesehatan lingkungan antara lain tidak ada sarana pengolahan air limbah (IPAL) dan sarana pencucian linen. Pembuangan air limbah ke septic tank dan pencucian linen dilakukan ke pihak ketiga sehingga tidak dapat dipantau kualitas pencuciannya. Kebersihan halaman dan sarana kesehatan lingkungan belum terpelihara dengan baik, seperti sarana jamban dan kamar mandi kurang bersih, pengelolaan sampah belum terkelola dengan baik khususnya sampah medis hanya dilakukan pengumpulan kemudian diserahkan ke pihak ketiga atau sebagian dilakukan pembakaran secara manual karena incinerator dalam keadaan rusak dan tidak ada pemisahan antara sampah organik dan anorganik.

\section{METODE}

Penelitian ini menggunakan metode deskriptif yaitu menggambarkan keadaan subyek penelitian pada saat sekarang berdasarkan fakta yang ada dan menggunakan check list dan kuesioner.

\section{III.HASIL DAN PEMBAHASAN}

\section{Hasil}

Kondisi kesehatan lingkungan Puskesmas Rawat Inap di kecamatan Kutowinangun Kabupaten Kebumen secara keseluruhan 66\% dengan kategori baik.

Hasil pengukuran suhu, kelembaban dan pecahayaan ruangan Puskesmas yang dilakukan pada pagi dan malam hari diperoleh rata-rata suhu pada pagi hari $28,25{ }^{\circ} \mathrm{C}$ dan pada malam hari $24,5{ }^{\circ} \mathrm{C}$. Pengukuran kelembaban ruang mendapatkan nilai rata-rata $66 \%$ pada pagi hari dan $79 \%$ pada malam hari. Pengukuran intensitas cahaya ruang rata-rata 159 lux pada pagi hari dan 124 lux pada malam hari.

Kondisi lingkungan dan bangunan bagian luar dan dalam ruangan Puskesmas dengan persentase $74 \%$ dikategorikan baik. Untuk fasilitas kesehatan lingkungan penyediaan air bersih Puskesmas dengan persentase $100 \%$ dikategorikan sangat baik, sarana pembuangan air limbah dengan persentase $83 \%$ dikategorikan sangat baik, sarana jamban dan kamar mandi dengan persentase $42 \%$ dikategorikan cukup, sarana pencucian linen dengan persentase $37 \%$ dikategorikan kurang, pengelolaan sampah dengan persentase $55 \%$ dikategorikan cukup, pengendalian vektor dan binatang pengganggu dengan persentase $33 \%$ dengan kategori kurang, pengolahan makanan dan minuman dengan persentase $75 \%$ dikategorikan baik, dan fasilitas penunjang dengan persentase $75 \%$ dikategorikan baik.

\section{Pembahasan}

Hasil pengukuran suhu udara di ruang Puskesmas Rawat Inap Kutowinangun terlihat pada table 4.3 dan tabel 4.4 didapatkan hasil suhu rata-rata $28,25{ }^{\circ} \mathrm{C}$ pada pagi hari dan suhu rata-rata pada malam hari $24,5^{\circ} \mathrm{C}$. Bila di bandingkan dengan KepMenkes RI Nomor 142/MENKES/SK/XII/2006 tentang Pedoman Penyelenggaraan Kesehatan Lingkungan bahwa suhu di setiap ruang sesuai dengan kondisi setempat $26-28{ }^{\circ} \mathrm{C}$ kecuali ruang obat, gudang obat, ruang laboratorium, dan ruang radiology adalah 22$27{ }^{\circ} \mathrm{C}$. Pada hasil pengukuran dapat dikatakan bahwa rata-rata suhu udara di ruang Puskesmas Rawat Inap Kutowinangun belum memenuhi syarat. Hal tersebut dikarnakan ventilasi belum menjamin peredaran udara di dalam ruangan Puskesmas dan beberapa ruangan belum diberi pengawaan secara mekanis. Fungsi sebuah sistem ventilasi dalam ruangan 
dimaksudkan untuk mengatur kondisi kenyamanan ruangan, memperbaruhi udara dengan pencemaran udara ruangan pada batas normal, serta menjaga kebersihan udara dari kontaminasi. Ventilasi ruangan secara alami didapatkan dengan jendela terbuka yang mengalirkan udara luar ke dalam ruangan. Pada ruangan yang suhunya $>30 \quad{ }^{\circ} \mathrm{C}$ sebaiknya menggunakan kipas angin atau Air Conditioner (AC) untuk memberikan rasa nyaman dan Pada dasarnya mekanisme kerja AC dengan mengalirkan udara dari luar gedung dilakukan proses pendinginan, selanjutnya udara yang dingin itu dihembuskan ke dalam ruangan.

Hasil pengukuran kelembaban udara di ruang Puskesmas Rawat Inap Kutowinangun didapatkan hasil kelembaban rata-rata $66 \%$ pada pagi hari dan $79 \%$ pada malam hari. Bila dibandingkan dengan KepMenkes RI Nomor 1428/MENKES/SK/XII/2006 tentang pedoman penyelenggaraan kesehatan lingkungan bahwa kelembaban disetiap ruangan sesuai dengan kondisi daerah setempat 40-60\% dan ruang obat, gudang obat, laboratorium dan radiologi 40-70\%. Pada hasil pengukuran dapat dikatakan bahwa rata-rata kelembaban udara di ruang Puskesmas Rawat Inap Kutowinangun belum memenuhi syarat. Kelembaban ruangan yang tinggi menyebabkan jamur pada dinding, bercak noda pada dinding, dinding rusak dan bau pengap pada ruangan. Tinggi rendahnya kelembaban udara di suatu tempat sangat bergantung pada beberapa faktor yaitu suhu, tekanan udara, pergerakan angin. kuantitas dan kualitas penyinaran, ketersediaan air di suatu tempat (air, tanah, perairan). Oleh sebab itu ruangan dibuat atap atau dinding kaca agar sinar matahari dapat membantu mengatur kelembaban dan periksa pipa saluran air yang bocor, meskipun bocor kecil dan lambat tetapi dalam waktu yang lama dapat menyebabkan kerusakan bangunan.

Hasil pengukuran intensitas cahaya di ruang Puskesmas Rawat Inap Kutowinangun didapatkan hasil intensitas cahaya rata-rata 159 lux pada pagi hari dan 124 lux pada malam hari. Bila dibandingkan dengan KepMenkes RI Nomor 1428/MENKES/SK/XII/2006 tentang pedoman penyelenggaraan kesehatan lingkungan bahwa intensitas cahaya disetiap ruangan 100-200 lux kecuali ruang Laboratorium, UGD, dan persalinan 300 lux dan dapur 100 lux. Pada hasil pengukuran dapat dikatakan bahwa intensitas cahaya ruang Puskesmas sudah memenuhi syarat. Untuk pencahayaan alami sebaiknya memperhatikan beberapa faktor agar memberikan keuntungan diantara distribusi dari terangnya cahaya, lokasi, pemantulan cahaya, jarak antar bangunan, letak geografis dan kegunaan bangunan gedung.

Kondisi lingkungan dan bangunan bagian luar Puskesmas Rawat Inap Kutowinangun yaitu pagar, halaman dan tempat parkir, teras, dinding bagian luar, atap dan langit-langit dan saluran buangan air hujan dalam kategori baik dengan presentase 68\%. Hasil observasi Puskesmas memiliki batas yang jelas dengan diberi pagar puskesmas yang membatasi lingkungan Puskesmas dengan lingkungan luar Puskesmas tetapi terdapat lumut yang menempel pada pagar dan juga dinding dan langit-langit bagian luar Puskesmas. Halaman puskesmas belum tersedianya tempat sampah, teras yang retak dan tidak rata menyebabkan genangan air pada saat hujan dan bisa menjadi perindukan vektor nyamuk. Hal tersebut belum sesuai dengan KepMenkes 1428/MENKES/SK/XII/2006 tentang pedoman penyelenggaraan kesehatan lingkungan Puseksmas bahwa untuk halaman tersedia tempat penampungan sampah sementara minimal dua tempat sampah untuk sampah organik dan anorganik, Puskesmas memiliki batas yang jelas dengan diberi pagar yang kuat dan bersih dari noda atau lumut, tidak ada genangan air dan pada halaman. Untuk memberikan kepuasan pada pasien maka kenyamanan, kebersihan dan kerapihan lingkungan Puskesmas harus diperhatikan.

Sedangkan untuk lingkungan dan bangunan bagian dalam pada dinding bagian dalam Puskesmas Rawat Inap Kutowinangun dengan kondisi dinding kategori baik yaitu 61\%. Dinding tidak retak, permukaan rata, warna terang (cream dan putih), tetapi sebagian dinding tidak dalam keadaan bersih adanya jamur dan lumut yang menempel pada dinding dan dinding tidak terbuat dari porselin. Bila dibandingkan dengan KepMenkes No 1428/MENKES/SK/XII/2006 tentang pedoman penyelenggaraan kesehatan lingkungan Puskesmas, sebaiknya kebersihan dinding beberapa ruangan perlu ditingkatkan, dinding yang selalu terkena percikan air dibuat kedap air dan khusus untuk dinding radiologi dibuat dengan ketebalan tertentu sesuai ketentuan yang berlaku agar tidak terjadi kebocoran radiasi dan dinding berwarna gelap.

Kondisi pada pintu, jendela, kaca dan ventilasi bagian dalam Puskesmas Rawat Inap Kutowinangun dengan kategori baik yaitu 71\%. Pintu, jendela, kaca sudah dalam keadaan baik yaitu dapat mencegah masuknya serangga, tikus dan binatang pengganggu tetapi pintu pada ruangan tertentu misalnya ruang perawatan dan ruang poli belum menggunakan pintu yang menutup secara otomatis dan pintu ruang radiologi dilapisi dengan plat timbal. Ventilasi pada masing-masing ruangan belum menjamin peredaran udara didalam ruangan, ruangan panas dan pengap apabila banyak penghuni diruang tersebut maka perlu adanya penghawaan mekanis (kipas angin/AC), dan masing-masing ventilasi setiap ruangan sebaiknya diberi kawat kasa tidak permanen agar mudah dibersihkan.

Kondisi atap dan langit-langit bagian dalam Puskesmas Rawat Inap Kutowinangun dengan kategori baik yaitu $75 \%$. Atap dan langit-langit masing-masing ruangan tidak bocor, mudah dibersihkan, langit-langit minimal 2,5 m dari lantai dan langit-langit rata dan tidak retak namun kebersihan atap dan langit kurang baik, minimal 
langit-langit dibersihkan minal 1 minggu satu kali. Ruangan yang belum terdapat langit-langit seperti ruang TU, dapur dan mushola sebaiknya lebih diperhatikan kebersihannya dan sebaiknya diberi langit-langit sesuai peraturan KepMenkes No 1428/MENKES/SK/XII/2006 tentang pedoman penyelenggaraan kesehatan lingkungan Puskesmas yaitu langit-langit mudah dibersihkan, dicat warna terang dan tinggi minimal 2,7 dari lantai.

Lantai bagian dalam Puskesmas Rawat Inap Kutowinangun, kondisi lantai dengan kategori baik yaitu $75 \%$. Lantai keseluruhan ruangan kedap air, mudah dibersihkan, bersih tetapi sebagian ruangan lantai tidak rata dan retak pada ruang tunggu, ruang rapat, ruang apotik dan ruang prawatan. Bila dibandingkan dengan KepMenkes No 1428/MENKES/SK/XII/2006 tentang pedoman penyelenggaraan kesehatan lingkungan Puskesmas sebaiknya lantai terbuat dari bahan yang kedap air, permukaan rata, tidak licin, dan mudah dibersihkan,

Kondisi tata ruangan dan penerangan bagian dalam Puskesmas Rawat Inap Kutowinangun dengan kategori baik yaitu $66 \%$. Keseluruhan ruangan penerangan cukup untuk membaca pada sudut yang gelap meskipun harus dengan penerangan buatan (lampu), penataan ruangan sebaiknya ditata rapi sesuai dengan fungsinya, penyimpanan arsip dilindungi dengan bahan anti rayap.

Fasilitas kesehatan lingkungan penyediaan air bersih Puskesmas Rawat Inap Kutowinangun dari segi kuantitas sudah memenuhi syarat yaitu sebesar 15-20 liter/hari ditambah dengan 40-60 liter/bad/hari. Air bersih di puskesmas bersumber dari PDAM dan sumur gali, kualitas air secra fisik sudah memenuhi persyaratan Permenkes No 416/menkes/Per/IX/1990 tentang syarat-syarat dan pengawasan kualitas air yaitu air tidak berbau, tidak berasa. Penyediaan air bersih tersedia pada masing-masing ruang seperti ruang laboratorium, ruang poli gigi, ruang apotek, ruang KIA, UGD, ruang radiologi dan ruang pengobatan. Selain kualitas air secara fisik, kualitas air secara kimia dan bakteriologis harus dilakukan pemeriksaan secara berkala apakah air tersebut memenuhi syarat atau tidak dengan melakukan pengambilan, pengiriman, pemeriksaan sampel air dan melakukan analisis hasil inspeksi sanitasi pemeriksaan laboratorium sehingga dapat meninjaklanjuti berupa perbaikan sarana dan kulitas air. Melakukan inspeksi sanitasi sarana air bersih dilksanakan minimal satu tahun sekali dan pemeriksaan kimia air bersih dua kali dalam satu tahun.

Sarana pembuangan air limbah Puskesmas sudah menggunakan saluran tertutup, kedap air, dan limbah menggalir dengan lancar sarta terpisah dengan saluran air hujan. Pembuangan air limbah yang dihasilkan dari kegiatan Puskesmas disalurkan ke septictank tidak dilakukan pengolahan air limbah. Puskesmas Rawat Inap Kutowinangun menghasilkan limbah medis tetapi belum dilakukan pengolahan air limbah. Bila dibangkan dengan KepMenkes No 1204/Menkes/SK/X/2004 tentang persyaratan kesehatan lingkungan rumah sakit Limbah yang dihasilkan dari kegiatan Puskesmas yang berasal dari kegiatan medis sebaiknya memiliki instalasi pengolahan air limbah (IPAL) dan limbah cair yang menggandung zat radioaktif pengelolaannya dilakukan sesuai ketentuan BATAN. Untuk air limbah yang dari dapur tidak saluran ke septictank tetapi dibuang ke selokan terbuka maka sebaiknya dibuang melalui saluran air limbah yang kedap air, bersih dari sampah dan dilengkapi penutup dan bak kontrol dan dilengkapi penangkap lemak.

Sarana jamban dan kamar mandi kontruksi terbuat dari bahan yang kuat, kedap air, tidak licin dan mudah dibersihkan. Tersedianya kamar mandi dan WC untuk karyawan dan pengujung, kamar mandi antara laki-laki dan perempuan tidak terpisah dan perbandingan jumlah karyawan dan pengunjung dengan jumlah kamar mandi belum sesuai, berdasarkan peraturan No 1428/MENKES/SK/XII/2006 tentang pdoman penyelenggaraan kesehatan lingkungan puskesmas bahwa untuk perbandingan jumlah karyawan dan pengunjung dengan jumlah kamar mandi dan jamban yaitu untuk karyawan 1 kamar mandi dan jamban untuk 15 orang dan untuk pengunjung 3 kamar mandi dan jamban untuk 10 orang. Untuk menjaga kebersihan kamar mandi dan jamban sebaiknya dilakukan menguras bak mandi minimal 2 kali seminggu dan pembersihkan kontruksi ruang dan bangunan kamar mandi dan jamban secara rutin, adanya pemisahan kamar mandi dan jamban antara laki-laki dan perempuan, pembuangan air limbah dari toilet dan kamar mandi dilengkapi dengan penahan bau, dan dilengkapi selogan atau peringatan untuk memelihara kebersihan.

Sarana tempat pecucian linen di Puskesmas berkerjasama dengan pihak ketiga. Pengumpulan linen kotor td ada pemilahan antara linen infeksius dan non infeksius dan penyimpanan linen bersih tidak dipisah menurut jenisnya. Penampungan linen kotor hanya diletakan pada bak terbuka dan ruangan berdekatan dengan pengolahan makanan dan penyimpanan linen bersih tidak tertata dengan rapih dan pintu lemari tidak dalam keadaan selalu tertutup. Menurut peraturan KepMenkes No 1204/MENKES/SK/X/2004 persyaratan kesehatan lingkungan rumah sakit, untuk linen yang tidak memiliki laundry tersendiri tetapi berkerjasama dengan pihak ketiga pada saat pengumpulan sebaiknya linen infeksius dan non infeksius dipisah menurut jenisnya dan memasukannya dalam kantong plastik, dan penyimpanan linen bersih harus dipisahkan menurut jenisnya dan tertata rapih, linen yang baru diterima ditempatkan di lemari bagian bawah dan pintu lemari selalu dalam keadaan tertutup.

Pengelolaan sampah yang dihasilkan oleh Puskesmas Rawat Inap Kutowinangun berupa 
sampah medis dan non medis. Pembuangan sampah di Puskesmas sudah cukup baik karena pada setiap ruangan terdapat tempat sampah dan pengangkutan sampah non medis (organik dan anorganik) setiap hari sekali, untuk penanganan sampah medis masih kurang karena sampah medis dimusnahkan melalui pihak ke tiga yaitu MoU ke Mirit atau Purworejo. Pada penampungan sementara sampah medis tidak tertutup dan diletakan di ruangan yang berdekatan dengan dapur. Bila dibandingkan dengan KepMenkes No 1204/MENKES/SK/X/2004 tentang persyaratan kesehatan lingkungan rumah sakit, Pengumpulan dan pengangkutan sampah medis sebaiknya menggunakan troli khusus yang tertutup dan penyimpanan sampah medis harus sesuai iklim tropis yaitu pada saat musim hujan paling lama 48 jam dan musim kemarau paling lama 24 jam. Tempat sampah yang tersedia di Puskesmas kedap air, tetapi tidak tertutup dan tidak adanya pemisahan sampah organik dan anorganik dan tidak diberi kantong plastik sesuai dengan jenis dan warnanya. Untuk lebih meningkatkan kebersihan lingkungan Puskesmas sebaiknya tempat sampah terbuat dari bahan yang kuat, ringan, tahan karat, kedap air, dan sampah organik, anorganik dan sampah medis terpisah dengan dilengkapi kantong plastik berwarna kuning untuk sampah medis dan berwarna hitam untuk sampah domestik, dan benda-benda tajam dan jarum di tampung pada wadah khusus.

Pengendalian tikus, serangga dan binatang pengganggu di Puskesmas rawat Inap Kutowinangun masih kurang, binatang pengganggu yang sering dijumpai yaitu lalat. Lalat dapat menimbulkan gangguan seperti hinggap pada makanan dan mengganggu ketenangan serta dapat menularkan penyakit secara mekanis. Secara keseluruhan ruangan di Puskesmas tidak adanya pemasangan kawat kasa pada ventilasi sehingga memungkinkan nyamuk masuk dalam ruangan terutama ruang perawatan. Bila dibandingkan Kep Menkes No 1204/MENKES/SK/X/2004 tentang persyaratan kesehatan lingkungan rumah sakit sebaiknya untuk pengendalian serangga, tikus dan binatang pengganggu petugas Puskesmas melakukan pengamatan jentik nyamuk sekurang-kurangnya setiap 1 minggu sekali untuk mengetahui ada atau tidaknya populasi jentik nyamuk, dan pemberian kawat kasa pada lubang ventilasi. Mengamati keberadaan kecoa yang ditandai dengan adanya kotoran, telur kecoa, dan kecoa hidup atau mati secara visual dengan bantuan senter setiap 2 minggu sekali. Memantau secara berkala setiap 2 bulan sekali ditempat yang menjadi perkembangbiaknya tikus yang ditandai dengan adanya kotoran, bekas gigitan, bekas jalan dan tikus hidup pada bangunan yang tertutup. Mengamati dan memantau keberadaan tikus dan ajing secara berkala dan mengukur kepadatan lalat secara berkala.

Pengolahan makanan dan minuman Puskesmas pembelian bahan makan di Puskesmas rawat inap di peroleh dari pasar Kutowinangun dan took-toko terdekat Puskesmas, penyimpanan bahan makanan diletakan pada lemari es dan dilakukan pembersihan terlebih dahulu, pengolahan makanan 3 kali pengolahan pada pagi, siang dan sore hari dan penyajian makanan dialkukan 3 kali penyajian yaitu pada pagi, siang dan sore dengan menggunakan wadah atau troli yang tertutup dan makanan yang disajkan makanan yang baru saja diolah. Penyajian makanan dan minuman di Puskesmas sudah memenuhi persyaratan sesuai KepMenkes/1204/MENKES/SK/X/2004 tentang persyaratan kesehatan lingkungan rumah sakit bahwa penyajian makanan dan minuman harus terhindar dari pencemaran dan makanan jadi yang sudah menginap tidak boleh disajikan kepada pasien. Tempat pengolahan makanan (dapur) sebelum dan setelah digunakan sebaiknya diberisihkan dengan antiseptic, asap dikeluarkan melalu cerobong yang dilengkapi dengan sungkup asap dan intensitas cahaya diupayakan tidak kurang dari 100lux. Penjamah makanan harus sehat dan bebas dari penyakit menular dan dipriksa kesehatannya minimal 2 kali setahun, sebelum dan sesudah bekerja mencuci tangan dan setelah keluar dari kamar kecil dan menggunakan pakaian kerja minimal menggunkan celemek.

\section{IV.KESIMPULAN}

Kondisi kesehatan lingkungan Puskesmas Rawat Inap di kecamatan Kutowinangun kabupaten Kebumen secara keseluruhan dikategorikan baik dengan persentase $66 \%$. Adapun fasilitas kesehatan lingkungan yang belum baik antara lain belum dilakukan pemeriksaan air bersih secara fisik, kimia, dan biologi, tidak ada intalasi pengolahan air limbah, perbandingan jamban dan kamar mandi dengan pengunjung atau karyawan masih kurang, penampungan sementara pencucian linen bersih dan kotor tidak tertpisan dan tidak tertutup, sampah anorganik dan organik belum terpisah, pengendalian vektor dan binatang pengganggu belum dilakukan, dan kebersihan lingkungan dan bangunan kurang terjaga. Pengukuran rata-rata suhu pada pagi hari $28,25^{\circ} \mathrm{C}$ dan $24,5^{\circ} \mathrm{C}$ pada malam hari. Pengukuran kelembaban rata-rata pada pagi hari $66 \%$ dan $79 \%$ pada malam hari. Pengukuran intensitas cahaya ratarata pada pagi hari 159 lux dan 124 lux pada malam hari.

Saran untuk penelitian selanjutnya sebaiknya dilakukan mengukur kuantitas air bersih dan pemeriksaan air bersih secara fisik, kima, dan biologi, mengukur kuantitas sampah, mengukur BOR dan data infeksi nosocomial

\section{DAFTAR PUSTAKA}

Tri Cahyono, 2014, Petunjuk Penyusunan Proposal Penelitian dan Karya Tulis Ilmiah, Purwokerto: Kementrian Kesehatan RI 
Politeknik Kesehatan Depkes Semarang Jurusan Kesehatan Lingkungan

Direktorat Jendral PPM\&PLP dan Direktorat Jendral Pelayanan Medik Departemen Kesehatan Rebublik Indonesia, 1955, Pedoman Sanitasi Rumah sakit di Indonesia, Jakarta: Depkes Republik Indonesia

Djamaludin Ramlan \& Maisye Marlyn Kuhu, 2013, Petunjuk Praktis Penulisan Penelitian Deskriptif, Purwokerto: UPT Percetakan dan Penerbitan Universitas Jenderal Soedirman

Djamaludin Ramlan \& Maisye Marlyn Kuhu, 2013, Dasar Statistik Penelitian, Purwokerto: UPT Percetakan dan Penerbitan Universitas Jenderal Soedirman

Keputusan Menteri Kesehatan

Rebublik Indonesia Nomor

1204/MENKES/SK/X/2004 Tentang

Persyaratan kesehatan Lingkungan Rumah Sakit, Jakarta: Depkes Rebublik Indonesia

Departemen Kesehatan Ri \& Ditjen PPM\&PL, 2003, Pedoman Pelaksanaan Klinik Sanitasi Untuk Puskesmas, Jakarta: Departemen Kesehatan RI

H.J. Mukono, 2006, Prinsip Dasar Kesehatan Lingkungan Edisi Dua, Surabaya: Pusat Penerbitan dan Percetakan Unair (AUP)
Keputusan Menteri Kesehatan Rebublik Indonesia Nomor 1428?MENKES/SK/XII/2006 Tentang Pedoman Penyelenggaraan Kesehatan Lingkungan Puskesmas, Jakarta: Depkes Rebublik Indonesia

Majalah Properti, 2013 at https://udararuang.wordpress.com/2013/12/02/ rumah-lembab-dan-kesehatan diakses pada tanggal 23 Juni 2015

Rendi Septyadi, 2009, Studi Sanitasi Ruang Rawat Inap Rumah Sakit Umum Hidayah Purwokerto Tahun 2009, Karya Tulis Ilmiah, Purwokerto: Kementrian Kesehatan RI Politeknik Kesehatan Semarang Jurusan Kesehatan Lingkungan

$$
\text { Undang-Undang Rebublik }
$$
Indonesia Nomor 36 Tahun 2009, Jakarta: Depkes Rebublik Indonesia

Profil Puskesmas Kutowinangun Tahun 2014

P.Wulansari, 2013, Tinjauan Pustaka at http://ejournal.uajy.ac.id, diakses pada tanggal $\underline{8 \text { Desember } 2014 \text { pukul } 18.00}$ 